\title{
Jurnal Majalah Ilmiah
}

\author{
https://jmi-upiyptk.org/ojs
}

2021 Vol. 28 No. $1 \quad$ Hal: 13-18 p-ISSN: $1412-5854$, e-ISSN: $\underline{2502-8774}$

\section{Perancangan Web Design Aplikasi E-Learning dengan Metode Prototype pada Tingkat SMA}

\author{
Frederica Rosabel Ramli ${ }^{1}$, Fikri Hakim², Ria Anggelina Hutabarat ${ }^{3}$ \\ $1,2,3$ Universitas Putra Indonesia YPTK, Padang \\ fredericarosabe1@gmai1.com
}

\begin{abstract}
Technology has experienced very rapid development at this time and has brought changes and has a positive and negative impact on human life. One of the fields currently contaminated by technological developments is the field of education, especially in Indonesia, where at first the learning system was still manual-based and is currently developing into an online learning system. It is clear that various levels of schools and universities have used technology to support their learning process and apply it. One of the uses of technology in the field of education is learning management systems (NGOs) such as e-learning. The use of e-learning as a learning medium has a function to improve the quality of student learning and help improve student understanding in learning. However, there are still many schools that have not implemented e-learning in their teaching and learning process, such as high school (SMA). Therefore, the design of this e-learning application web design is expected to help several schools that require an online learning system that is user friendly so that schools can be better prepared to follow current development trends.
\end{abstract}

Keyword : Website, System, Application Design, E-Learning, Prototype

\begin{abstract}
Abstrak
Teknologi telah mengalami perkembangan yang sangat pesat saat ini dan membawa perubahan serta memberikan dampak positif dan negatif dalam kehidupan manusia.Salah satu bidang yang saat ini terkontaminasi oleh perkembangan teknologi iyalah bidang pendidikan khususnya di Indonesia, dimana pada awalnya sistem pembelajaran masih berbasis manual dan pada saat ini berkembang menjadi sistem pembelajaran online. Terlihat jelas diberbagai jenjang sekolah maupun universitas sudah banyak memanfaatkan teknologi dalam penunjang proses belajar mereka serta menerapkannya. Pemanfaatan teknologi dalam bidang pendidikan sendiri salah satunya adalah Learning management system (LSM) seperti e-learning. Pemanfaatan e-learning sebagai media belajar memiliki fungsi untuk meningkatkan kualitas belajar siswa serta membantu meingkatkan pemahaman siswa dalam belajar Akan tetapi masih banyak sekolah-sekolah tingkatan yang belum menerapkan e-learning dalam proses belajar mengajar mereka, seperti Sekolah Menengah Atas (SMA). Maka dari itu, perancangan web design aplikasi e-learning ini dirancang diharapkan dapat membantu beberapa sekolah yang memerlukan sistem pembelajaran secara online yang bersifat user friendly sehingga sekolah-sekolah dapat lebih siap dalam mengikuti tren perkembangan jaman sekarang ini.
\end{abstract}

Kata Kunci: Website, Sistem, Desain Aplikasi, E-learning,Prototype

(C) 2021 Majalah IImiah UPI YPTK 


\section{Pendahuluan}

Teknologi telah mengalami perkembangan yang sangat pesat saat ini, dimana perkembangan teknologi itu sendiri membawa perubahan dalam kehidupan manusia, serta memberikan dampak positif dan negatif yang dapat dirasakan secara langsung maupun tidak langsung oleh manusia itu sendiri. Salah satu bidang yang saat ini terkontaminasi oleh perkembangan teknologi iyalah bidang pendidikan. Pendidikan merupakan suatu bentuk usaha yang dimana bersifat terencana supaya dapat menciptakan suasana dan proses pembelajaran yang aktif serta dapat menumbuhkan dan mengembangkan potensi yang dimiliki para siswa (Technische Universtität München, 2018).

Pada saat ini, seiring berjalannya waktu, perkembangan dunia pendidikan mulai terlihat banyaknya perubahan yang terjadi, dimana dahulu manusia masih melakukan proses belajar mengajar masih secara manual, yang artinya mereka masih menggunakan media papan tulis dan buku serta teknik pembelajaran yang diharuskan bertatap muka agar memaksimalkan proses belajar mengajar mereka, dan lain halnya di ranah digital sekarang, dimana perkembangan teknologi sangat membawa dampak pada perkembangan dunia pendidikan.

Pendidikan di Indonesia sendiri menjadi salah satu negara yang terkontaminasi dengan adanya perkembangan teknologi, terlihat jelas diberbagai sekolah maupun universitasuniversitas sebagian sudah menerapkan teknologi dalam menunjang kebutuhan proses belajar mengajar mereka. Perkembangan teknologi ini membawa dampak positif yang sangat besar dimana dapat dimanfaatkan didalam dunia pendidikan. Pemanfaatan teknologi dalam bidang pendidikan sendiri salah satunya adalah Learning management system (LSM) seperti e-learning.

LSM (Learning management system) merupakan suatu sistem pembelajaran yang dapat mengatasi permasalahan metode pembelajaran konvensional dan dapat menanggulangi kekurangan waktu belajar siswa (Teuku Fadjar Shadek, 2017). Software LSM yang banyak digunakan pada sekolah dan universitas iyalah e-learning.

Pemanfaatane-learning sebagai media belajar memiliki fungsi untuk meningkatkan kualitas belajar siswa serta membantu meingkatkan pemahaman siswa dalam belajar(Novita \& Andiarni, 2019). Dengan menggunakan $e$ learning dapat lebih membantu proses belajar mengajar disekolah menjadi lebih baik

Pada saat ini, di Indonesia masih banyak sekolah-sekolah tingkatan yang belum menerapkan e-learning dalam proses belajar mengajar mereka, salah satunya iyalah Sekolah Menengah Atas (SMA). Maka dari itu, perlunya pemerataan sistem pendidikan di Indonesia supaya melahirkan sekolah-sekolah berkualitas yang dapat memenuhi kriteria Sekolah Standart Nasional,serta untuk mencegah ketertinggalan sekolah-sekolah pada segi teknologi.

Untuk menyetarakan pendidikan SMA yang belum menggunakan e-learning dalam proses belajar mengajar mereka, diangkatlah sebuah penelitian oleh peneliti yaitu : Perancangan Web Desaign Aplikasi E-Learning dimana dirancang untuk membantu beberapa sekolah yang memerlukan sistem pembelajaran secara online, sehingga sekolah-sekolah dapat lebih siap dalam mengikuti tren perkembangan jaman sekarang. Perancangan ini dibuat menggunakan metode Prototype dengan desaign sesuai dengan keinginan user dan akan bersifat User Friendly yang diharapkan dapat memenuhi keinginan calon pengguna.

E-learning terdiri dari 2 bagian, yaitu " $\mathrm{e}$ " yang merupakan singkatan dari elektronik dan "learning" yang berarti "pembelajaran".

Pengertian e-learning sendiri banyak dinyatakan oleh para ahli dari segi dan sudut pandang yang berbeda, tetapi arti dan maknanya iyalah sama. E-learning yaitu suatu bentuk kegiatan pelatihan yang dimana menggunakan media elektronik sebagai alat perantaranya. ELearning juga merupakan suatu bentuk pendidikan yang menggabungkan motivasi, komunikasi, efisiensi dan teknologi.(Prayudi, 2009). Sedangkan prototype menurut Darmawan adalah salah satu versi dari sebuah sistem potensial yang memberikan ide bagi para pengembang dan calon pengguna, bagaimana sistem akan berfungsi dalam bentuk yang telah selesai. Metode ini merupakan suatu proses pembentukan model untuk memberikan gambaran dasar mengenai alat dalam tahap awal pengujian.(Saputra \& Pramujati, 2013).

Dalam penelitian kami yang berjudul "Perancangan Web Desaign Aplikasi E-learning Dengan Metode Prototype Pada Tingkat SMA" ini sebelumnya juga sudah pernah diteliti dan dibuat oleh Mukhlishoh Syaukati Robbi, Yulianti dengan judul penelitian "Perancangan Aplikasi E-Learning Berbasis Web dengan Model Prototype pada SMPN 7 Kota Tangerang Selatan".

Semoga dengan diterapkannya sistem e-learning ini diharapkan dapat meningkatkan kualitas pendidikan siswa pada tingkat SMA, diiharapkan juga setiap SMA yang akan menerapkan aplikasi e-learning dapat memenuhi kriteria Sekolah Standart Nasional serta mampu 
menggali dan menjabarkan spesifikasi kebutuhan proses pembelajaran secara lebih detail sehingga sesuai dengan kebutuhan.

\section{Metodologi Penelitian}

Metode utama yang digunakan yaitu Metode Prototyping.Metode Prototyping perangkat lunak adalah salah satu metode siklus hidup sistem yang didasarkan pada konsep model bekerja (working model).

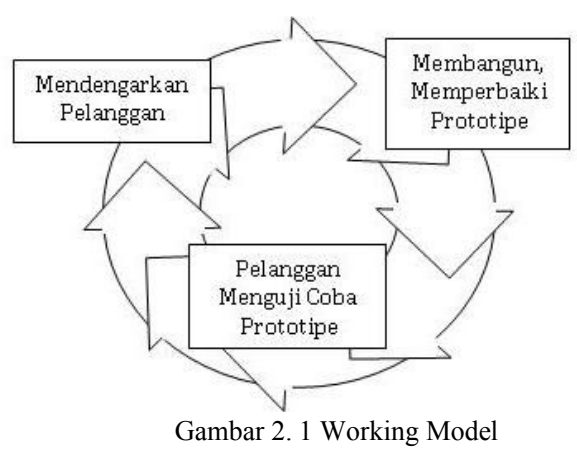

Berikut adalah langkah-langkah dalam membuat perancangan sistem aplikasi e-learning dengan menggunakan metode prototype:

1. Pengumpulan kebutuhan

Pelanggan dan pengembang bersama-sama mendefinisikan format seluruh perangkat lunak, mengidentifikasikan semua kebutuhan, dan garis besar sistem yang akan dibuat. Pelanggan atau pengguna web ini adalah guru dan siswa-siswi SMA sehingga web di desain sesuai dengan kebutuhan yang bersangkutan.

2. Membangun prototyping

Membangun prototyping dengan membuat perancangan sementara yang berfokus pada penyajian kepada pelanggan (misalnya dengan membuat input dan format output). Dalam perancangan web design aplikasi e-Learning, terlebih dahulu membuat rancangan DFD dari aplikasi E-Learnning yang akan dibentuk. Gambaran DFD dari sistem yang akan digunakan yakni sebagai berikut:

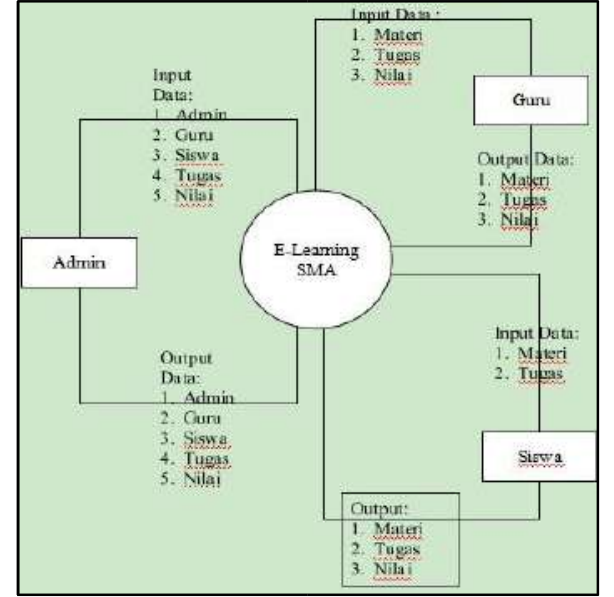

Gambar 2.2. Data Development Diagram

3. Evaluasi protoptyping

Evaluasi ini dilakukan oleh pelanggan apakah prototyping yang sudah dibangun sudah sesuai dengan keinginan pelanggan. Jika sudah sesuai maka langkah 4 akan diambil. Jika tidak prototyping direvisi dengan mengulang langkah 1, 2, dan 3 (perubahan desain).

4. Mengkodekan system/implementasi sistem

Dalam tahap ini prototyping yang sudah di sepakati diterjemahkan ke dalam bahasa pemrograman yang sesuai dan dilakukan penerapan yaitu memvisualkan desain sistem e-learning yang telah disetujui antara user dan pengembang

\section{Menguji system}

Setelah sistem sudah menjadi suatu perangkat lunak yang siap pakai, harus dites dahulu sebelum digunakan.untuk memasitikan sistem e-learning yang dikembangkan berjalan lancar tanpa adanya kesalahan atau error, serta memastikan keluaran yang dihasilkan sesuai dengan yang diinginkan Pengujian ini dilakukan dengan White Box, Black Box, Basis Path, pengujian arsitektur dan lain-lain.

6. Evaluasi Sistem

Pelangganmengevaluasi apakah sistem yangsudah jadi sudah sesuai dengan yang diharapkan.Jika ya, langkah 7 dilakukan; jika tidak, ulangi langkah 4 dan 5 .

7. Menggunakan sistem /Pemeliharaan sistem

Perangkat lunak yang telah diuji dan diterima pelanggan siap untuk digunakan. 


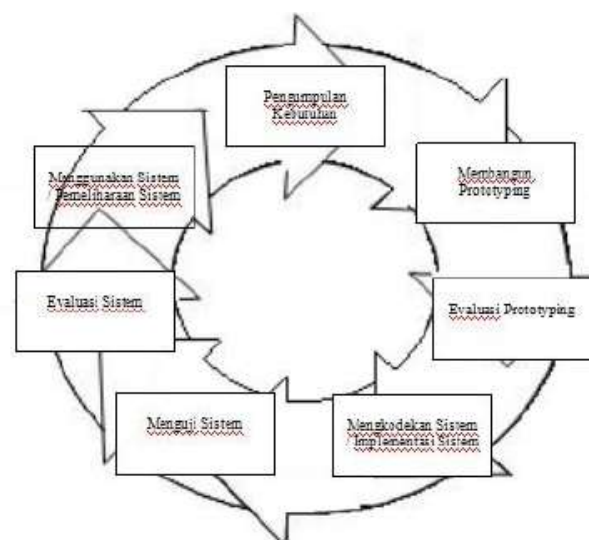

Gambar 2.3 Bagan Langkah Pengujian Perangkat Lunak

\section{Pembahasan Dan Hasil}

Untuk pengisian data akan dibutuhkan perancangan database agar data yang diinputkan dapat tersimpan dan dapat ditampilkan pada output. Ketentuan Database akan dibagi menjadi beberapa bagian tabel meliputi tabel Guru, tabel Materi atau Tabel Mata Pelajaran, tabel Siswa dan tabel Nilai. Di dalam tabel terdapat beberapa istilah yang memiliki fungsi : field berfungsi untuk menyimpan informasi yang diinputkan, type berfungsi menunjukkan tipe data yang disimpan dalambentuk karakter, length berfungsi untuk menunjukkan ukuran dari sebu file dalam karaktr, dan primry key berfungsi sebagai identitasuntuk membedakan data yang tersimpan pada tabel.

Tabel3.1 Tabel Guru

\begin{tabular}{llll}
\hline Field & Type & Length & $\begin{array}{l}\text { Primary } \\
\text { Key }\end{array}$ \\
\hline Kode Guru & Char & 10 & $*$ \\
Nama Guru & Varchar & 35 & No Text \\
Bidan Studi & Varchar & 30 & No Text \\
No Telp & Char & 12 & No Text \\
Email & Varchar & 35 & No Text \\
\hline
\end{tabular}

Tabel3.2 Mata Pelajaran / Tabel Materi

\begin{tabular}{|c|c|c|c|}
\hline Field & Type & Length & $\begin{array}{l}\text { Primary } \\
\text { Key }\end{array}$ \\
\hline $\begin{array}{l}\text { Kode } \\
\text { Pelajaran }\end{array}$ & ${ }^{\text {Mata }}$ Char & 10 & $*$ \\
\hline $\begin{array}{l}\text { Nama } \\
\text { Pelajaran }\end{array}$ & ${ }^{\text {Mata }}$ Varchar & 35 & No Text \\
\hline
\end{tabular}

Tabel3.3 Siswa

\begin{tabular}{llll}
\hline Field & Type & Length & $\begin{array}{l}\text { Primary } \\
\text { Key }\end{array}$ \\
\hline Kode Siswa & Char & 10 & $*$ \\
Nama Siswa & Varchar & 35 & No Text \\
Email & Varchar & 35 & No Text \\
\hline \multicolumn{5}{c}{ Tabel 3.4 Nilai } & \\
\hline Field & Type & Length & Key \\
\hline Kode Nilai & Char & 10 & $*$ \\
Kode & Mata & & \\
Pelajaran & Char & 10 & $*$ \\
Semester & Varchar & 1 & No Text \\
Tahun Ajaran & Varchar & 10 & No Text \\
Nilai Tugas & Integer & 3 & No Text \\
Keterangan & Varchar & 25 & No Text \\
\hline
\end{tabular}

\section{Hasil Tampilan}

Tampilan Menu Login Admin

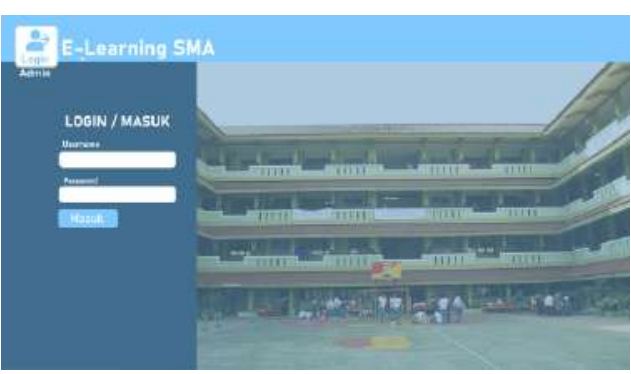

Gambar 3.1 Tampilan Login Admin

Tampilan Menu Login Siswa atau Guru

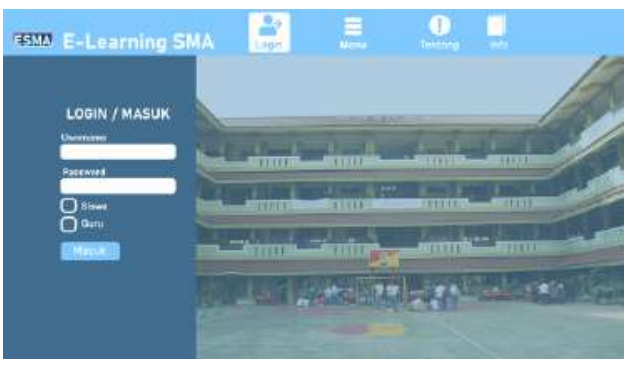

Gambar 3.2 Tampilan Memu Login Siswa atau Guru

Tampilan Menu Pilihan Sebagai Siswa 


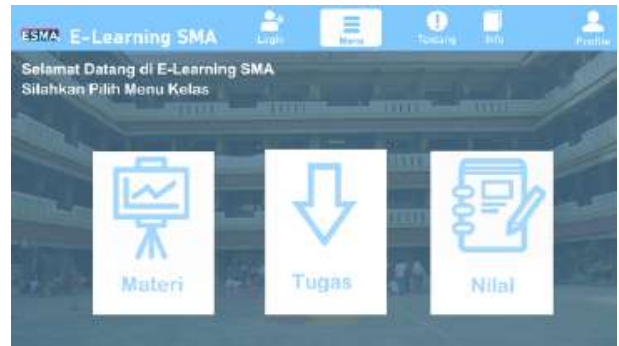

Gambar 3.3 Tampilan Menu Siswa

Tampilan Menu Materi / Mata Pelajaran

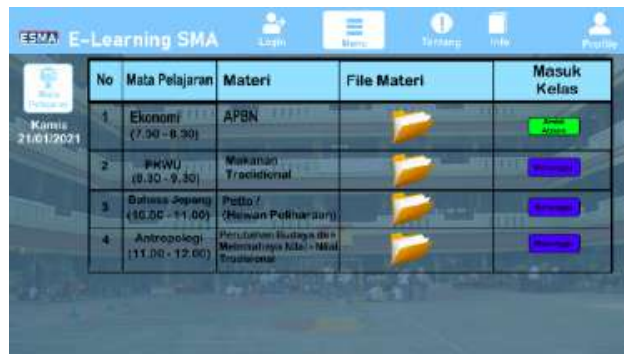

Gambar 3.4 Tampilan Menu Materi Pelajaran

Menu Tugas Kelas

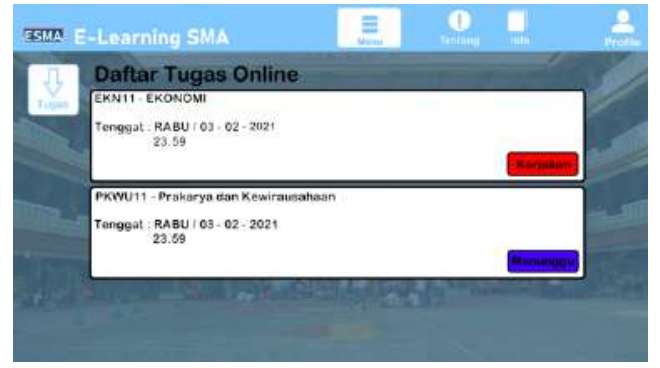

Gambar 3.5 Tampilan Menu Tugas Kelas

Pengumpulan Tugas

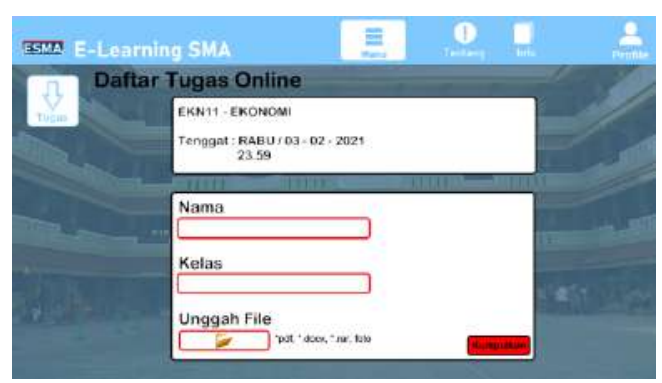

Gambar 3.6 Tampilan Pengumpulan Tugas Profile

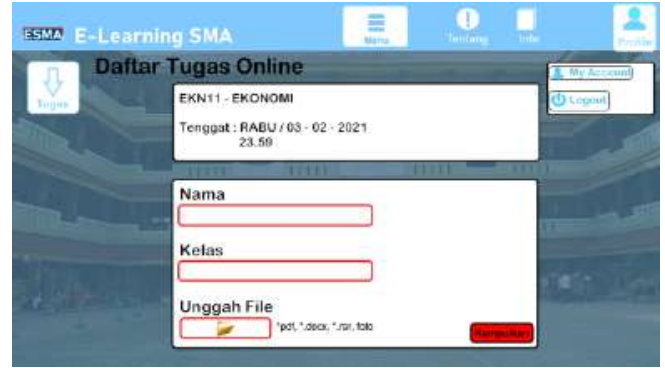

Gambar 3.7 Tampilan Profile

Profile Siswa

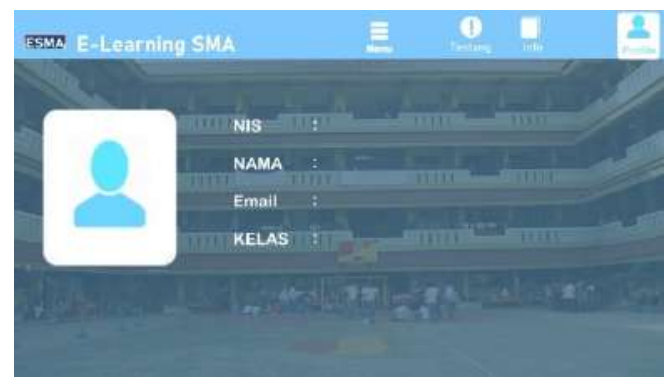

Gambar 3.8 Tampilan Profil Siswa

Ujian Online

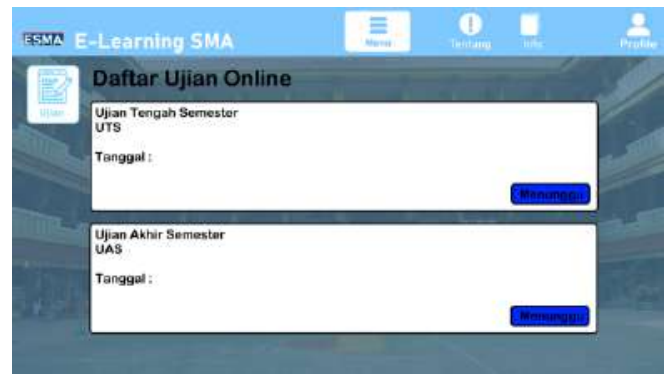

Gambar 3.9 Tampilan Menu Ujian Online Menu Guru

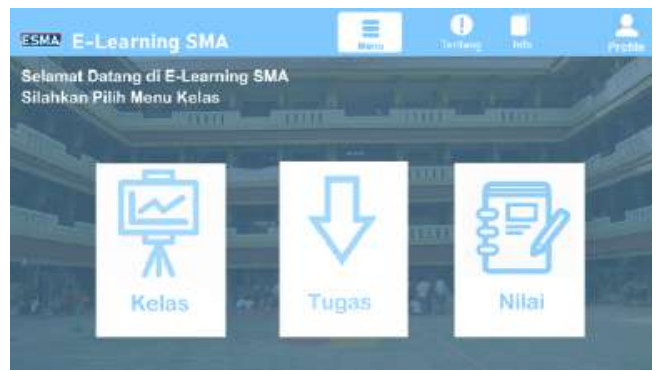

Gambar 3.10 Tampilan Menu Guru 


\section{Kesimpulan}

Berdasarkan penelitian dan penulisan yang telah diuraikan mengenai perancangan web desaign aplikasi e-learning dengan menggunakan metode prototype pada tingkat SMA, maka dapat disimpulkan bahwa Rancangan design web aplikasi e-learning dapat membantu beberapa sekolah tingkat SMA yang belum menggunakan sistem pembelajaran secara elearning.Rancangan desaign web aplikasi elearning ini dapat digunakan bukan hanya pada saat jam pelajaran saja, akan tetapi di luar jam pelajaran juga dapat dipergunakan.Rancangan desaign web aplikasi di rancang sesuai dengan keinginan user.

\section{Daftar Rujukan}

1. Novita, A., \& Andiarni, A. (2019). Prototipe E-Learning Untuk Pendalaman Dan Evaluasi Materi Pembelajaran Pada Smpn 1 Samigaluh. Jurnal Ilmu Pen, 4(2), 211-216.

2. Prayudi, Y. (2009). Kajian Awal: E-
Learning Readiness Index ( Elri ) Sebagai Model Bagi Evaluasi E-Learning Pada Sebuah Institusi. Snati.

3. Rulia Puji Hastanti, Bambang Eka Purnama, I. U. W. (2015). Sistem Penjualan Berbasis Web (E-commerce Pada Tata Distro Kabupaten Pacitan. Jurnal Bianglala Informatika, 3(2). https://doi.org/10.1007/s13226-018-02845

4. Saputra, D. R. H., \& Pramujati, B. (2013). Rancang Bangun Prototype Unmanned Aerial Vehicle (UAV) dengan Tiga Rotor. Jurnal Teknik Pomits.

5. Technische Universtität München, L.-M.U. M. (2018). 済無No Title No Title. $E$ Conversion - Proposal for a Cluster of Excellence, 1(1), 60-68.

6. Teuku Fadjar Shadek, R. S. (2017). Pengembangan Aplikasi Sistem ELearning Pada Seluruh Mata Kuliah Dengan Menggunakan Program Hypertext Prepocessor ( Php ) Dalam Rangka Peningkatan Mutu Proses Dan Hasil Pembelajaran. Jurnal ProTekInfo, 4, 1-18. 